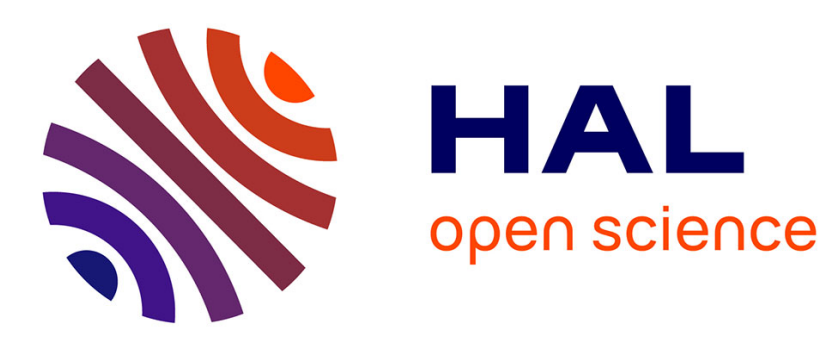

\title{
Genome editing by CRISPR-Cas9 technology in Petunia hybrida
}

\author{
M. Chopy, Pierre Morel, S. Rodrigues Bento, M. Vandenbussche
}

\section{To cite this version:}

M. Chopy, Pierre Morel, S. Rodrigues Bento, M. Vandenbussche. Genome editing by CRISPR-Cas9 technology in Petunia hybrida. Acta Horticulturae, 2020, 1283, pp.209-218. 10.17660/ActaHortic.2020.1283.28 . hal-02999116

\section{HAL Id: hal-02999116 https://hal.science/hal-02999116}

Submitted on 10 Nov 2020

HAL is a multi-disciplinary open access archive for the deposit and dissemination of scientific research documents, whether they are published or not. The documents may come from teaching and research institutions in France or abroad, or from public or private research centers.
L'archive ouverte pluridisciplinaire HAL, est destinée au dépôt et à la diffusion de documents scientifiques de niveau recherche, publiés ou non, émanant des établissements d'enseignement et de recherche français ou étrangers, des laboratoires publics ou privés. 


\section{Genome editing by CRISPR-Cas9 technology in Petunia hybrida}

M. Chopy, P. Morel, S. Rodrigues Bento and M. Vandenbussche

Laboratoire Reproduction et Développement des Plantes, Univ Lyon, ENS de Lyon, UCB Lyon 1, CNRS, INRA, F69342, Lyon, France

Abstract

CRISPR-Cas9 technology has been shown to be a very powerful tool to generate targeted mutations in a wide range of species. To evaluate its applicability for standard gene functional analysis in Petunia, we performed a case study aimed at obtaining lossof-function alleles for six different Petunia genes. Using single guide RNAs (sgRNA), we obtained between 1 to 3 putative null alleles for 5 out of the six genes. Here we describe in detail the obtained results and the protocol used in this study, and discuss some of the technical problems encountered. Although the efficiency of the protocol should be further increased, these results demonstrate that CRISPR-Cas9 technology represents a very useful addition to the available molecular toolkit in petunia.

Keywords: reverse genetics, targeted mutation, flower development, petunia, genome editing, CRISPR-Cas9.

INTRODUCTION

Petunia is a major ornamental crop species but at the same time also has a long history as a model species in plant research (Gerats and Vandenbussche, 2005). Indeed, its short life cycle, easy culture conditions, easy propagation both sexual and asexual, easy transformation procedure, the availability of its genome sequence (Bombarely et al., 2016) and large dTph1 transposon mutant collections (Koes et al., 1995; Vandenbussche et al., 2008) make petunia a powerful genetic model to study a variety of biological processes (Vandenbussche et al., 2016).

Several tools have been established for gene functional analysis in petunia: 
Together with tobacco, petunia was one of the first plant species that were successfully used to create stable transgenic plants (Horsch et al., 1985). Since then, the function of many genes have been determined using overexpression and RNAi/cosuppression approaches. As in tobacco, VIGS (virus induced gene silencing) works also very efficiently in petunia ( Chen et al., 2004; Broderick et al., 2014). However, both RNAi/cosuppression and VIGS silencing approaches are notorious for downregulating other genes exhibiting partially homologous regions, and moreover, silencing of such other genes may occur at the post-transcriptional (Stam et al., 1997). Therefore, it might become very difficult to assess the specificity of the silencing constructs, since measuring of only the mRNA levels of homologous genes may not be sufficient to demonstrate specificity.

In contrast, insertion mutagenesis and associated selection of multiple independent insertion alleles allows to determine gene function much more accurately. In petunia, cloning of the endogenous dTph1 transposable element (Gerats et al., 1990, 2013) allowed to develop highly efficient transposon insertion mutagenesis approaches, both for forward and reverse genetics screens (Koes et al., 1995; Van den Broeck et al., 1998; Vandenbussche et al., 2003, 2008). However, although large populations for reverse genetics in have been developed, a proportion of the genes in the petunia genome remains untagged, demonstrating the main limitation of the system.

More recently, a new revolutionary mutagenesis method called CRISPR-Cas9 technology has started to prove its efficiency, leading to its immensely growing success within the plant community (reviewed in Liu et al., 2017). In short, the CRISPR-Cas9 mechanism is based on the use of a Cas9 nuclease coupled with a guide RNA (gRNA), and when introduced together, they will lead to DNA double-strand breaks at the targeted site (Puchta and Fauser, 2014). Reparation mechanisms occur rapidly, and in plants the most frequent event of repair is the Non-Homologous End Joining (NHEJ) inducing insertions or deletions. In a less frequent manner, Homology Direct Repair (HDR) can also occur. The application of CRISPR-Cas9 technology in petunia has already been demonstrated in three recent works (Zhang et al., 2016; Morel et al., 2018; Xu et al., 2019). Zhang and colleagues have targeted the phytoene desaturase $(P D S)$ gene coding for a key enzyme in carotenoid biosynthesis, the visual screen was easy because the $p d s$ mutation leads to an albino phenotype. Later Morel and co-workers used CRISPR-Cas9 technology for the purpose of analyzing flower development. In this work they have targeted a C-class gene called pMADS3 (PM3) to precisely define its role in nectary development. Finally, in order to enhance Petunia flower longevity, Xu and colleagues have 
targeted a gene involved in the ethylene biosynthesis (ACO1: 1-Aminocyclopropane-1Carboxylate Oxidase).

To further evaluate the use of CRISPR-Cas9 technology for standard gene functional analysis in petunia, we have performed a case study aimed at obtaining loss-of-function alleles for six different petunia genes. Here we describe in detail the obtained results and the protocol used in this study, which may be helpful for other research groups wanting to establish petunia CRISPR-Cas9 mutagenesis in the lab. 


\section{MATERIALS AND METHODS}

\section{Plant material}

The Petunia line Mitchell (also known as W115) was used in all Agrobacteriummediated transformation experiments. This is a doubled haploid from a hybrid between $P$. axillaris and the cultivar 'Rose of Heaven'. It is the most popular variety used to generate transgenic lines. WT Mitchell and derived transgenic or edited plants were grown in growth chambers. The photoperiod consisted of 16 hours light $\left(23-25^{\circ} \mathrm{C}\right)$ and 8 hours darkness (18$20^{\circ} \mathrm{C}$ ) in a 24 hours diurnal cycle.

\section{Vector construction}

Mutant alleles were generated using the protocol and vectors described by Schiml and colleagues (Schiml et al., 2016). Protospacer sequences were designed according to the criterions described by Schiml et al. (2016). We further verified by sequencing that they matched with Mitchell WT sequences. Protospacer sequences used in this study and their corresponding primers are listed in Table 1 . Then the 5'-protospacer-3' PAM sequences were cloned by restriction into the pEN-Chimera vector (Schiml et al., 2016), giving the pENChimera-X vector ( $\mathrm{X}=$ targeted gene). Gateway LR recombination was carried out using $\mathrm{pEN}$ Chimera-X and ProDE-Cas9, leading to the production of the plant transformation vectors pDE-Cas9-X. All these vectors were verified by sequencing.

\section{Petunia transformation with Agrobacterium}

These final vectors were introduced in electrocompetent Agrobacterium tumefaciens (AGL0 strain). The day before plant transformation, Agrobacterium cultures were grown overnight in $5 \mathrm{~mL}$ LB liquid medium with $5 \mu \mathrm{L}$ of Spectinomycine (stock $100 \mathrm{mg} / \mathrm{mL}$ ). Starting from the petunia transformation day, all the following steps were realized under the hood. In the morning, the overnight Agrobacterium cultures were centrifuged at 3500rpm 10 minutes, the LB liquid was removed, and the pellet was resuspended with $45 \mathrm{~mL}$ of sterile water, plus $4.5 \mu \mathrm{L}$ of acetosyringone (stock $100 \mathrm{mM}$ ). In parallel, leaves from the "Mitchell" background were surface sterilized in $0.5 \%$ hypochlorite solution for 10 minutes and rinsed five times with sterile water. Sterilized leaves were cut with a scalpel blade into $0.5-1 \mathrm{~cm}^{2}$ small pieces and were put in the Agrobacterium suspension for around 20 minutes. Next, leaf fragments were placed between two layers of sterile filter papers for drying and were finally transferred 
to co-culture plate medium for two days in the dark at $21^{\circ} \mathrm{C}$. On day 2 , explants were directly transferred to fresh selective medium plates containing Glufosinate-ammonium (Basta) to select for the transgene and Carbenicilline as an antibiotic to kill Agrobacteria. The plates were sealed with parafilm and incubated at $21^{\circ} \mathrm{C}$ under moderate light (Osram biolux L36 W) in long days conditions (18h day, 6h night). Once a week leaf fragments were transferred to fresh selection medium until the apparition of shoots. Each individual shoot was excised from the calli and transferred to a rooting hormone-less medium. After rooting, plants were transplanted to soil and grown in a growth chamber. For a visual representation of the petunia transformation protocol and for medium composition to carry out petunia transformation, see Figure 1 and Table 2 respectively. Around 4 months were necessary from the protospacer design to the first regenerated T0 plants. The above described petunia transformation procedure is based on a classical transformation protocol (Napoli et al., 1990) with some modifications.

\section{Mutation detection}

Genomic DNA from each T0 plant was extracted according to Edwards et al., 1991, and a PCR was first performed using the primers SS42 and SS43 (Schiml et al., 2016) to screen for the presence of the Cas9-encoding cassette. Subsequently, T-DNA-positive lines were screened for the presence of gene editing events by PCR amplifying and sequencing of the targeted regions. Primers used for the screen are described in Table 1. 


\section{RESULTS}

\section{Petunia hybrida transformation results}

Six genes belonging to different transcription factor families were specifically selected for a gene targeting approach (Figure 2), since we were previously unable to identify transposon insertion alleles for these genes. For the CRISPR-cas9 procedure, we simply used vectors described by Schiml and colleagues (Schiml et al., 2016) implemented with our desired protospacer sequences. The design of these protospacer sequences was based on Mitchell variety DNA sequences (determined by Sanger sequencing for each targeted genes) since it's the variety used for the transformations in this study. Indeed, DNA sequences are not always fully conserved between the Mitchell variety and the routinely used Petunia axillaris or Petunia inflata genome sequences, as we observed in several instances. At the end seven vectors were generated with a single guide RNA ( $\operatorname{sgRNA}$ ), called sgRNA1 to sgRNA7 to target independently the different genes (Figure 2 and Table 1 ). Then stable transformations of petunia (Mitchell) leaves were carried out as it is described in the material and method section, and around 60 leaf discs were used for each transformation. After plant regeneration (around 3 months) we obtained between 2 to 24 Basta-resistant plants depending on the transformation experiment (Figure 3A). Genomic DNA from each T0 plant was extracted (1) to test for the presence of the T-DNA construct, and (2) to detect and characterize mutations in each of the targeted genes. With one exception, we found in all experiments an important proportion (frequently $>50 \%$ ) of the regenerated plants that lacked the T-DNA construct (Figure 3A), although they survived Basta selection. This relatively high degree of false positives likely can be diminished by applying more stringent selection media.

\section{Identification of CRISPR-Cas9 induced mutations}

The T-DNA-positive lines metioned above were subsequently screened to evaluate type and frequency of the mutation events. To do so, we have designed primers surrounding the sgRNA targeted site and Sanger sequencing was performed directly on the PCR products from each transgenic plants (see primers in Table 1). To discriminate plant lines as (1) homozygous WT, (2) homozygous mutants, (3) heterozygous, (4) bi-allelic or (5) chimeric we simply looked at chromatogram profile, expecting the mutation positions to be before and close to the PAM motif (Zuo and Liu, 2016). More precisely, in the case of homozygous alleles 
only one peak was expected to appear at each nucleotide position, and if it was the case, sequences were simply aligned with the WT sequence for comparison. In the case of heterozygous or bi-allelic plants, a maximum of two overlapping peaks at each nucleotide position starting from the mutated site(s) were expected. For those cases, we used the CRISPID software (GSL Biotech LLC) (Dehairs et al., 2016) to determine the sequence of the different alleles. In the case of complex chimeric plants, up to 4 different peaks can be expected at a single nucleotide position in the chromatogram. In such cases, off-spring of crosses with these plants should be analysed in order to determine the exact nature of the mutated alleles.

Of the in total 34 obtained T-DNA positive plants, (Figure 3B), we detected mutation events in 17 plants (50\%). This resulted in the identification of at least one mutant allele for six targeted sequences among the seven, varying from 1 to 3 different alleles generated. All edited alleles are summarized in Figure 2. By chance, all of the identified indels (ranging from $1 \mathrm{bp}$ to $41 \mathrm{bp}$ ) were not a multiple of three, thereby causing a frameshift downstream of the mutation site, and therefore possibly representing null alleles. T0 plants were further selfed to maintain the mutations. In parallel, crosses with WT plants were also realized in order to remove the CRISPR-Cas9 cassette. After genotyping analysis of the T1 lines, all the mutations described before were detected in the offspring with the expected Mendelian fashion. Mutations therefore clearly occurred during the callus formation leading to stable and fixed alleles in both somatic and germinal cells. Moreover, in case of the $p m 3 \mathrm{~T} 1$ generation, 9 plants among 24 plants conserved the CRISPR-Cas 9 cassette, and one of them present a new nullallele generated by a deletion of $41 \mathrm{bp}$ (Figure 2D) and the mutation was transmitted to the $\mathrm{T} 2$ generation. According to these results, we can conclude that CRISPR-Cas 9 can be active all along the life-cycle of the plant.

\section{Discussion}

Using CRISPR- Cas9 technology, we attempted to obtain loss-of-function alleles for six different genes. Using single guide RNAs (sgRNA), we obtained between 1 to 3 putative null alleles for 5 out of the 6 genes. These results demonstrate that CRISPR-Cas 9 technology can be routinely used for gene editing in petunia. Nevertheless, the whole procedure remains labour intensive and may be further optimized. First of all, starting from around 60 leaf fragments per transformation experiment, we obtained only few regenerated plants, and of these, there was a considerable proportion of false positives (not carrying the T-DNA construct). 
Recently a paper was published in which it was described that "elimination of macro elements from inoculation and co-cultivation media enhances the efficiency of Agrobacterium-mediated transformation in petunia" (Nobakht Vakili et al., 2018). It is worthwhile testing if this indeed would improve transformation rates. Otherwise, the number of leaf discs used for one transformation should be further increased. Increasing Basta concentration, or using other selective markers could further diminish false positives.

Despite the low rate of T-DNA-positive lines, we obtained in the end a reasonable mutation score $(50 \%)$ which is comparable to the proportion of the bleaching phenotype occurring in petunia T0 Basta-resistant plant lines (55.6\% and $87.5 \%$ ) obtained by Zhang and colleagues, 2016. Finally, compared to plant transformation in Arabidopsis, the biggest workload of the petunia transformation procedure is simply caused by the fact that it passes by in vitro plant regeneration. We therefore should hope that transformation protocols similar to the floral dip procedure in Arabidopsis will be developed for petunia in the future. 


\section{REFERENCES}

Bombarely, A., Moser, M., Amrad, A., Bao, M., Bapaume, L., Barry, C.S., Bliek, M., Boersma, M.R., Borghi, L., Bruggmann, R., et al. (2016). Insight into the evolution of the Solanaceae from the parental genomes of Petunia hybrida. Nat. Plants 2, 16074.

Broderick, S.R., Wijeratne, S., Wijeratn, A.J., Chapin, L.J., Meulia, T., and Jones, M.L. (2014). RNA-sequencing reveals early, dynamic transcriptome changes in the corollas of pollinated petunias. BMC Plant Biol. 14, 307.

Chen, J.-C., Jiang, C.-Z., Gookin, T., Hunter, D., Clark, D., and Reid, M. (2004). Chalcone synthase as a reporter in virus-induced gene silencing studies of flower senescence. Plant Mol. Biol. 55, 521-530.

Dehairs, J., Talebi, A., Cherifi, Y., and Swinnen, J.V. (2016). CRISP-ID: decoding CRISPR mediated indels by Sanger sequencing. Sci. Rep. 6, 28973.

Edwards, K., Johnstone, C., and Thompson, C. (1991). A simple and rapid method for the preparation of plant genomic DNA for PCR analysis. Nucleic Acids Res. 19, 1349.

Gerats, T., and Vandenbussche, M. (2005). A model system for comparative research: Petunia. Trends Plant Sci. 10, 251-256.

Gerats, A.G., Huits, H., Vrijlandt, E., Maraña, C., Souer, E., and Beld, M. (1990). Molecular characterization of a nonautonomous transposable element (dTph1) of petunia. Plant Cell 2, 1121-1128.

Gerats, T., Zethof, J., and Vandenbussche, M. (2013). Identification and Applications of the Petunia Class II Act1/dTph1 Transposable Element System. In Plant Transposable Elements: Methods and Protocols, T. Peterson, ed. (Totowa, NJ: Humana Press), pp. 223-237.

Horsch, R., Fry, J., Hoffman, N., Wallroth, M., Eichholtz, D., Rogers, S., Fraley, R., Hoffmann, N.L., and Eichholrz, D. (1985). A simple and general method for transferring genes into plants.

Koes, R., Souer, E., van Houwelingen, A., Mur, L., Spelt, C., Quattrocchio, F., Wing, J., Oppedijk, B., Ahmed, S., and Maes, T. (1995). Targeted gene inactivation in petunia by PCR-based selection of transposon insertion mutants. Proc. Natl. Acad. Sci. U. S. A. 92, 8149-8153.

Liu, X., Wu, S., Xu, J., Sui, C., and Wei, J. (2017). Application of CRISPR/Cas9 in plant biology. Acta Pharm. Sin. B 7, 292-302.

Morel, P., Heijmans, K., Ament, K., Chopy, M., Trehin, C., Chambrier, P., Bento, S.R., Bimbo, A., and Vandenbussche, M. (2018). The Floral C-Lineage Genes Trigger Nectary Development in Petunia and Arabidopsis. Plant Cell 30, 2020-2037.

Napoli, C., Lemieux, C., and Jorgensen, R. (1990). Introduction of a Chimeric Chalcone Synthase Gene into Petunia Results in Reversible Co-Suppression of Homologous Genes in trans. Plant Cell 2, 279-289.

Nobakht Vakili, A., Bagheri, H., and Azadi, P. (2018). Elimination of macro elements from inoculation and co-cultivation media enhances the efficiency of Agrobacterium-mediated transformation in Petunia. Physiol. Mol. Biol. Plants 24, 703-710. 
Puchta, H., and Fauser, F. (2014). Synthetic nucleases for genome engineering in plants: prospects for a bright future. Plant J. 78, 727-741.

Schiml, S., Fauser, F., and Puchta, H. (2016). CRISPR/Cas-Mediated Site-Specific Mutagenesis in Arabidopsis thaliana Using Cas9 Nucleases and Paired Nickases. Methods Mol. Biol. Clifton NJ 1469, 111-122.

Stam, M., Mol, J.N.M., and Kooter, J.M. (1997). The silence of genes in transgenic plants. Ann Bot 79, 3-12.

Van den Broeck, D., Maes, T., Sauer, M., Zethof, J., De Keukeleire, P., D’hauw, M., Van Montagu, M., and Gerats, T. (1998). Transposon Display identifies individual transposable elements in high copy number lines. Plant J. Cell Mol. Biol. 13, 121-129.

Vandenbussche, M., Zethof, J., Souer, E., Koes, R., Tornielli, G.B., Pezzotti, M., Ferrario, S., Angenent, G.C., and Gerats, T. (2003). Toward the Analysis of the Petunia MADS Box Gene Family by Reverse and Forward Transposon Insertion Mutagenesis Approaches: B, C, and D Floral Organ Identity Functions Require SEPALLATA-Like MADS Box Genes in Petunia. Plant Cell 15, 2680-2693.

Vandenbussche, M., Janssen, A., Zethof, J., Orsouw, N.V., Peters, J., Eijk, M.J.T.V., Rijpkema, A.S., Schneiders, H., Santhanam, P., Been, M.D., et al. (2008). Generation of a 3D indexed Petunia insertion database for reverse genetics. Plant J. 54, 1105-1114.

Vandenbussche, M., Chambrier, P., Rodrigues Bento, S., and Morel, P. (2016). Petunia, Your Next Supermodel? Front. Plant Sci. 7, 72.

Xu, J., Kang, B.-C., Naing, A.H., Bae, S.-J., Kim, J.-S., Kim, H., and Kim, C.K. (2019). CRISPR/Cas9mediated editing of 1-aminocyclopropane-1-carboxylate oxidase1 enhances Petunia flower longevity. Plant Biotechnol. J. 0.

Zhang, B., Yang, X., Yang, C., Li, M., and Guo, Y. (2016). Exploiting the CRISPR/Cas9 System for Targeted Genome Mutagenesis in Petunia. Sci. Rep. 6, 20315.

Zuo, Z., and Liu, J. (2016). Cas9-catalyzed DNA Cleavage Generates Staggered Ends: Evidence from Molecular Dynamics Simulations. Sci. Rep. 6, 37584. 
Table 1. Sequence description of primers used for this work. Underlined: Protospacer sequence and in boldface: Recombination site for cloning.

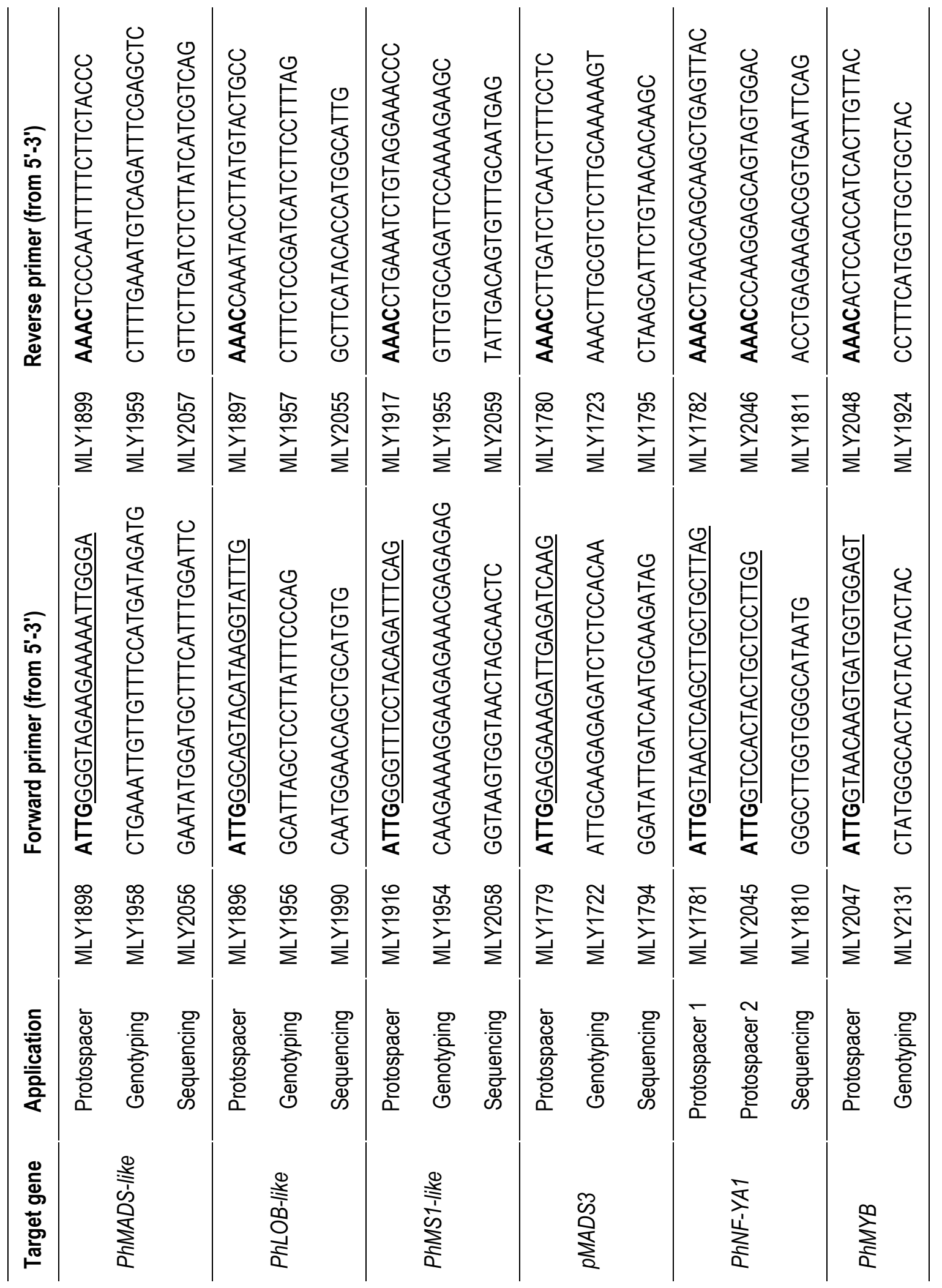


Table 2. Medium composition to carry out petunia transformation.

\begin{tabular}{|c|c|c|c|}
\hline & Co-culture medium & Selection medium & Rooting medium \\
\hline & 1 liter & 1 liter & 1 liter \\
\hline Ultrapure water & $800 \mathrm{~mL}$ & $800 \mathrm{~mL}$ & $800 \mathrm{~mL}$ \\
\hline Sucrose & $30 \mathrm{~g}$ & $30 \mathrm{~g}$ & $30 \mathrm{~g}$ \\
\hline MS basal salt mixture (Sigma) & $4,4 \mathrm{~g}$ & $4,4 \mathrm{~g}$ & $4,4 \mathrm{~g}$ \\
\hline \multirow{2}{*}{$\begin{array}{l}\text { Gamborg 's B5 Basal Medium } \\
\text { (stock } 1 \mathrm{mg} / \mathrm{mL} \text { ) }\end{array}$} & $1 \mathrm{~mL}$ & $1 \mathrm{~mL}$ & $1 \mathrm{~mL}$ \\
\hline & \multicolumn{3}{|c|}{$\begin{array}{l}\text { Adjust } \mathrm{pH} \text { between } 5,7 \text { and } 5,9 \text { with } \mathrm{NaOH} 1 \mathrm{M} \\
\text { Complete with ultrapure water to the final volume }\end{array}$} \\
\hline \multirow[t]{2}{*}{ Phytagel } & $4 \mathrm{~g}$ for a $1 \mathrm{~L}$ bottle & $4 \mathrm{~g}$ for a $1 \mathrm{~L}$ bottle & $4 \mathrm{~g}$ for a $1 \mathrm{~L}$ bottle \\
\hline & \multicolumn{2}{|c|}{ To add (sterile) depending on the medium: } & \\
\hline BAP (stock $1 \mathrm{mg} / \mathrm{mL}$ ) & $2 \mathrm{~mL}$ & $2 \mathrm{~mL}$ & $\mathrm{X}$ \\
\hline NAA (stock $1 \mathrm{mg} / \mathrm{mL}$ ) & $100 \mu \mathrm{L}$ & $100 \mu \mathrm{L}$ & $\mathrm{X}$ \\
\hline Acetosyringone (stock $100 \mathrm{mM}$ ) & $200 \mu \mathrm{L}$ & $x$ & $x$ \\
\hline Carbenicilline (stock 50 mg/mL) & $x$ & $5 \mathrm{~mL}$ & $5 \mathrm{~mL}$ \\
\hline Kanamycine (stock 50 mg/mL) & $x$ & $6 \mathrm{~mL}$ & $1 \mathrm{~mL}$ \\
\hline BASTA (stock 10 mg/mL) & $x$ & $0,75 \mathrm{~mL}$ & $0,1 \mathrm{~mL}$ \\
\hline Dispense & $\begin{array}{l}\text { Around } 33 \mathrm{~mL} / \\
\text { petridish }\end{array}$ & $\begin{array}{l}\text { Around } 40 \mathrm{~mL} / \\
\text { petridish }\end{array}$ & Around $50 \mathrm{~mL}$ / box \\
\hline
\end{tabular}




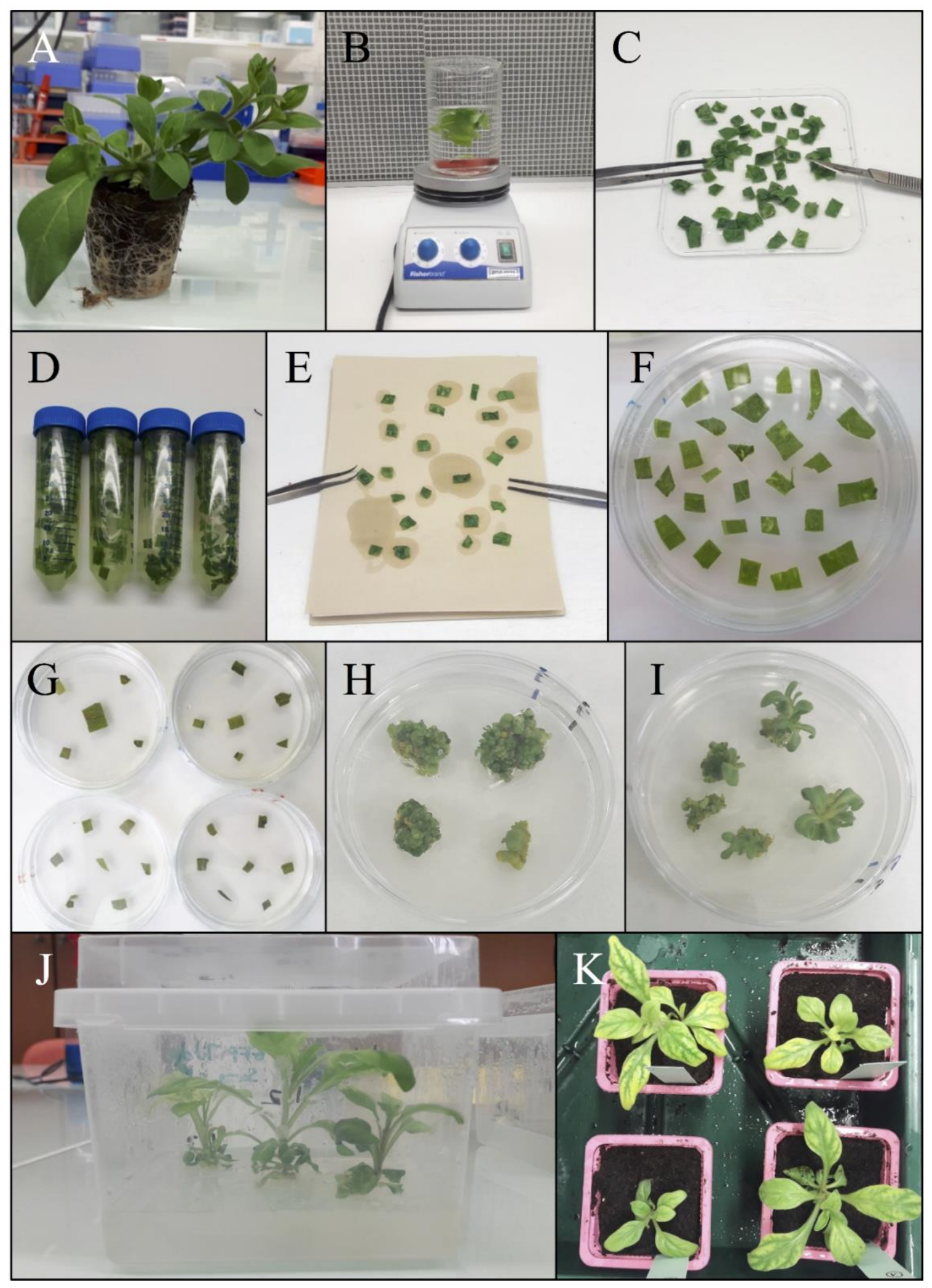


Figure 1. Petunia transformation protocol. (A) The transformable "Mitchell" line (B) Sterilization of leaves in $0.5 \%$ hypochlorite using a magnetic stirrer (C) Cutting explants (D) Liquid co-culture incubation of petunia leaf fragments and Agrobacterium during 20 minutes to attach the bacteria (E) Drying step between two layers of sterile filter papers (F) Transfer of the sterile explants to MS plates without antibiotics - co-culture for two days without light (G) Transfer of the explants to selective medium plates - BASTA selective medium (H-I) Formation of callus and then shoots $(\mathrm{J})$ Transfer of the individual shoot in a rooting medium (K) Once roots start to appear plants can be transferred in soil. 

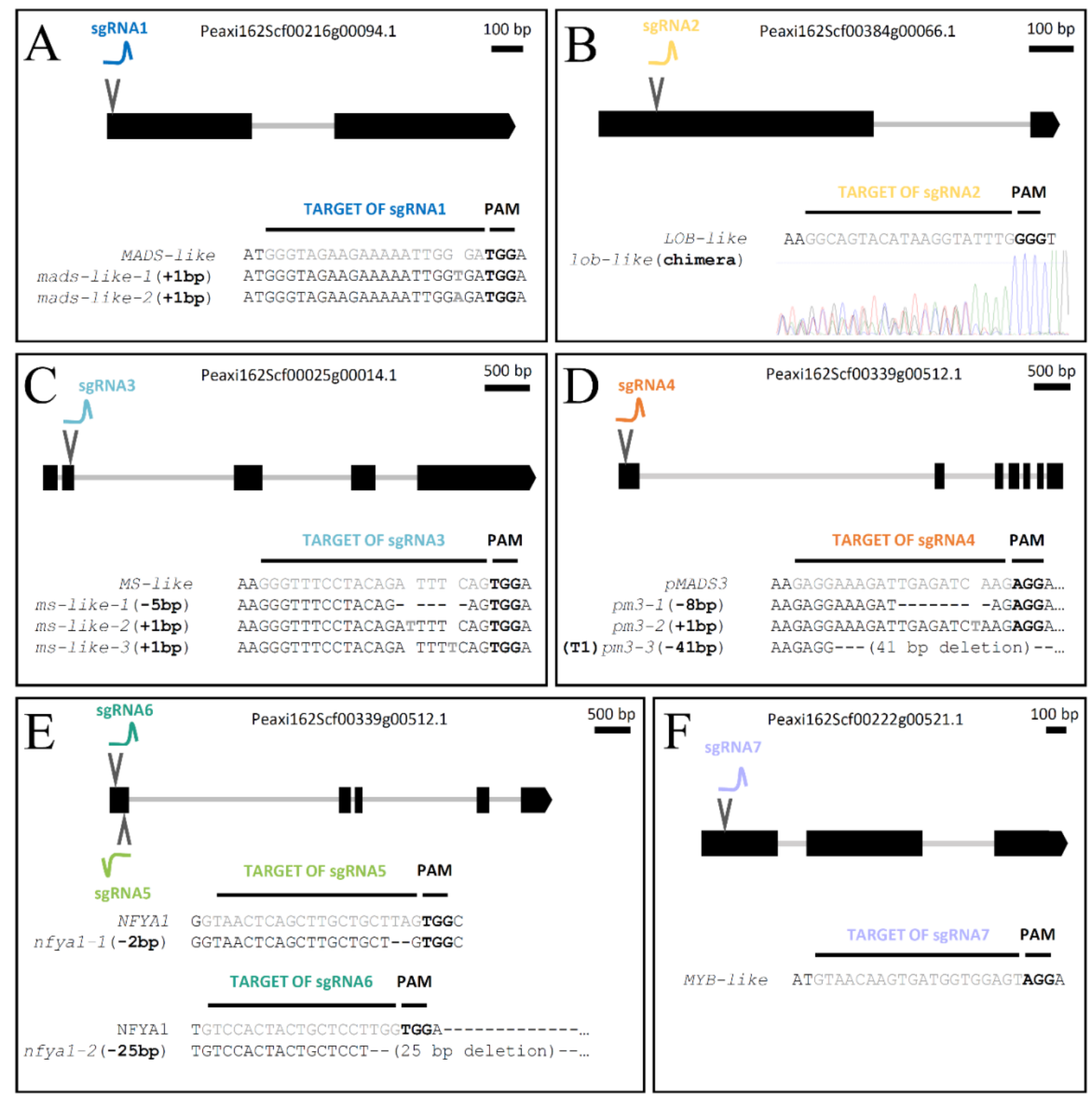

Figure 2. Edited alleles obtain after CRISPR-Cas 9 action on 6 genes. The genomic structure of each gene is represented by black boxes (exons) and grey lines (introns). The sgRNA targeted site is indicated by the triangle. Below the obtained alleles are aligned on the WT sequence. Protospacer sequences are in grey. (A) sgRNA1 targeting MADSlike gene Peaxi162Scf00216g00094.1 (B) sgRNA2 targeting LOB-like gene $\begin{array}{llll}\text { Peaxi162Scf00384g00066.1 } & \text { (C) sgRNA3 targeting MS-like gene }\end{array}$ $\begin{array}{lll}\text { Peaxi162Scf00025g00014.1 } & \text { (D) sgRNA4 targeting pMADS3 gene }\end{array}$ Peaxi162Scf00022g00098.1 (E) sgRNA5 and sgRNA6 independently targeting NFYA1 $\begin{array}{lllll}\text { Peaxi162Scf00339g00512.1 } & \text { (F) sgRNA7 targeting MYB-like gene }\end{array}$ Peaxi162Scf00222g00521.1. 


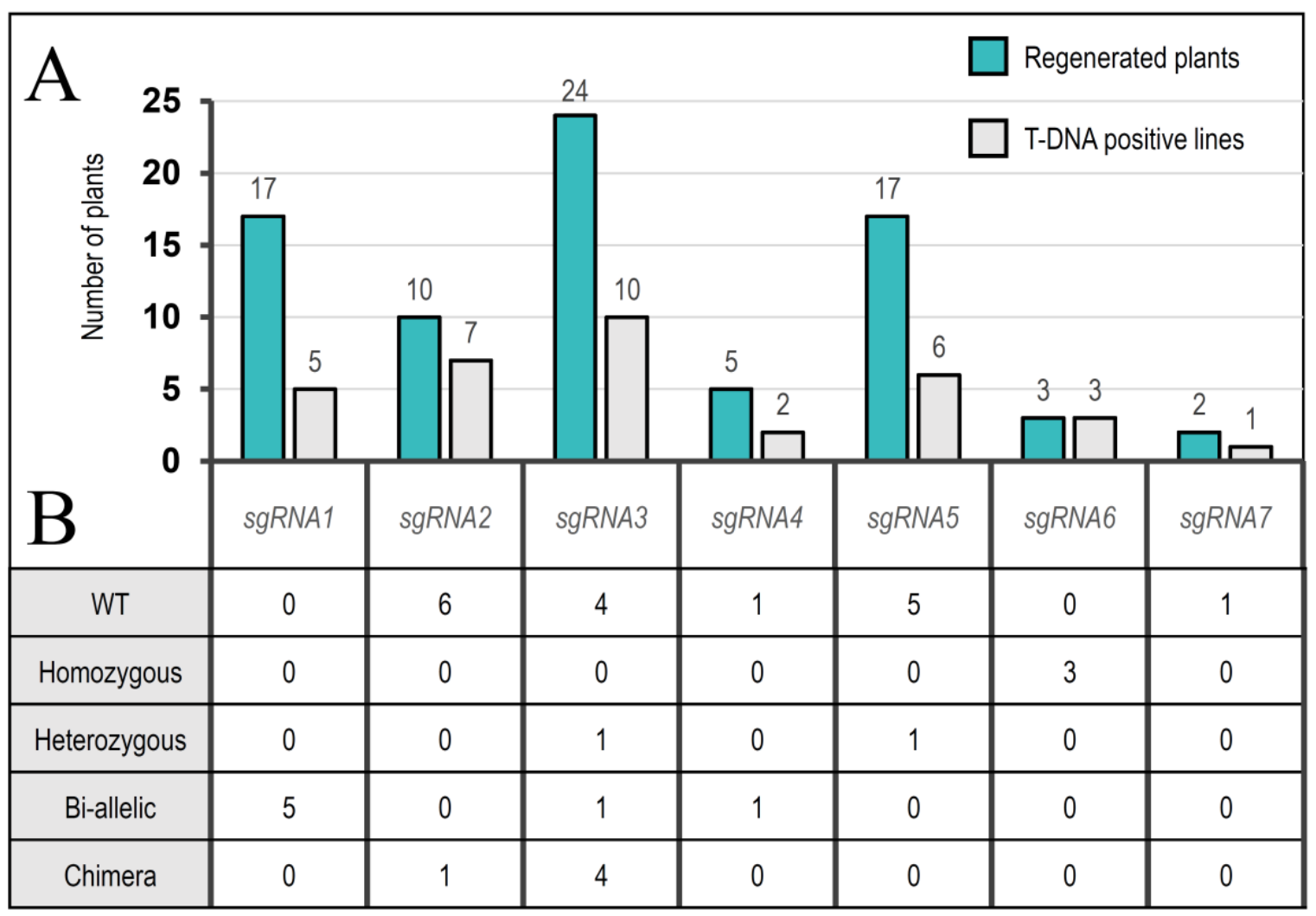

Figure 3. Identification of T-DNA positive lines and generation of new mutant alleles. (A) Graph summarizing the number of regenerated plants after Petunia transformations and the proportion of T-DNA positive lines identified after genotyping. Gene targeting experiments were performed for Peaxi162Scf00216g00094.1, Peaxi162Scf00384g00066.1, Peaxi162Scf00022g00098.1, Peaxi162Scf00025g00014.1, Peaxi162Scf00222g00521.1. (B) Table summarizing different categories of plants generated, namely WT, homozygous, heterozygous, bi-allelic and chimera among the T-DNA positive lines. 